\title{
Aportaciones literarias al relato de la nación católica española (1848-1868). La obra de Antonio Trueba*
}

\author{
Literary contributions to the story of the Spanish Catholic nation (1848- \\ 1868). The work of Antonio Trueba
}

\author{
Javier PÉREZ NúÑEZ \\ Universidad Autónoma de Madrid
}

\begin{abstract}
RESUMEN
Este ensayo constituye una sucinta aproximación al estudio histórico de la obra literaria escrita por Antonio Trueba durante la Monarquía isabelina. Con ella realiza una importante aportación a la difusión del modelo social y nacional conservador. Así, en la familia y en la aldea católicas encuentra los rasgos de una sociedad ejemplar: auténtica religiosidad, sanas costumbres y tradiciones, valor del trabajo, respeto a la propiedad, etc. Estos caracteres corresponden al pensamiento católico-conservador, que es el que profesa y en cuyo entorno articula sus principales relaciones sociales. De él procede, de una parte, su inclinación por el régimen político doctrinario y su visión retrospectiva y tradicional de la nación y de la historia de España. De otra parte, también deriva su adhesión al fuerismo vasco, participando de manera muy destacada en la creación de la imagen idílica del mundo rural vasco.
\end{abstract}

Palabras Clave

Literatura romántica; nación-católica; Monarquía isabelina; fuerismo vasco.

\section{ABSTRACT}

This essay constitutes a succinct approach to the historical study of the literary work written by Antonio Trueba during the reign of Isabel II, through which he makes an important contribution to the dissemination of the conservative social national model. To this end, within catholic families and villages he finds the traits of an exemplary society: authentic religiosity, healthy customs and traditions, the valuing of work, respect for property, etc. These features correspond to Catholic-conservative thinking, which is what he himself professes and is the environment within which he has his principal social relationships. His work demonstrates, on the one hand, his inclination for a doctrinary political regime and his retrospective and traditional vision of the nation and of the history of Spain. On the other, his adherence to the notion of Basque fuerism is clear and contributes in a very prominent way to the creation of the idyllic image of the Basque countryside.

\section{KEYWORDS}

Romantic literature; Catholic-nation; Elizabethan monarchy; Basque fuerism.

*. Una primera versión de este trabajo se presentó al Primer congreso internacional. Historia y Literatura: Intercambios culturales y creación de identidades, celebrado en la Facultad de Filosofía y Letras de la Universidad Autónoma de Madrid los días 26 y 27 de noviembre de 2021 y organizado por el proyecto de investigación HAR2016-76398-P, en que se encuadra. 
De un tiempo a esta parte, estamos estudiando desde una perspectiva histórica la obra literaria y ensayística del escritor, archivero y cronista de Vizcaya, Antonio Trueba Quintana (1819-1889). Comenzamos analizando los cuentos y poemas escritos durante el reinado isabelino para intentar descubrir los elementos con los que el escritor vizcaíno contribuye a la construcción de la primera versión del nacional catolicismo, esbozada por el ala más conservadora del moderantismo, en la que se sitúa. Continuamos abordando el estudio de una memoria elaborada en 1867 para la Diputación de Vizcaya y de textos literarios complementarios con los que Antonio Trueba presenta una imagen idílica del universo rural vasco, que tendrá gran trascendencia en el imaginario fuerista y, después, en el nacionalista. Finalmente, constatamos a través de la obra literaria y periodística cómo Antonio Trueba no es capaz de asumir la quiebra de los anteriores modelos e ideales provocada el desarrollo del sexenio democrático y la abolición foral perpetrada nada más inaugurarse la Restauración, y como reorienta su pensamiento hacia la afirmación de la nacionalidad vasca $^{1}$.

Las páginas siguientes se asientan en las aportaciones realizadas en los anteriores estudios, pero no son una síntesis de ellas. No lo son porque, si bien subrayan sus principales ideas, lo hacen desde una perspectiva diferente: se acercan a la obra de Antonio Trueba tomando como hilo conductor los momentos más trascendentales de su vida. Con ello, lo que se pretende es advertir como éstos afectan de manera notoria al quehacer literario y a la formación de las ideas nucleares de su pensamiento.

En las líneas autobiográficas que Antonio Trueba publica en 1889 en $\mathrm{La}$ Ilustración española y americana señala: "No sé quién ha dicho que son verdaderamente dichosos los pueblos que no tienen historia. Si esto reza también para las personas, yo debo ser muy dichoso, porque, mirada mi vida por fuera, casi, casi es la del más vulgar e in-historiable de los mortales”². Pues bien, ni una ni otra afirmación son del todo ciertas. La primera, porque considera al pueblo vasco particularmente dichoso, sobre todo durante la Monarquía isabelina, sin que por ello deje de contribuir a dotarle, si no de un potente sustrato histórico, cuando menos mitológico. La segunda aseveración también resulta dudosa porque quiere hacer trascender su vida, que le parece "vulgar e in-historiable”, a través de la literatura. Así, en algunas narraciones aparece como un personaje más que interviene en la trama, pretendiendo protagonizar el papel de maestro o cura de pueblo para intentar aleccionar a los lectores, a la luz de la moral católica conservadora, en los comportamientos que considera ejemplares y en los contrarios, que por ello estima deben ser censurados o castigados. En otras de sus obras está presente como el literato que es, casi siempre muy reconocido, admirado y querido

1. Javier PÉREZ NúÑEZ, "Didáctica para una nación católico-conservadora: los cuentos populares de Antonio Trueba”, Hispania Sacra, 72/146 (2020), pp. 551-567, https://doi.org/10.3989/hs.2020.041; ídem, "La comunidad imaginada por Antonio Trueba: ¿el paraíso foral vasco durante la monarquía isabelina?”, en Carmen DE LA GuARdia Herrero, Florencia PeYrou Tubert y Pilar Toboso SÁnchez (eds.), Escribir identidades. Diálogos entre historia y literatura, Madrid, Síntesis, 2020, pp. 45-73, e ídem “Antonio Trueba ante la Revolución de 1868 y la abolición foral: en el tránsito desde la literatura del doble patriotismo a la nacionalidad vasca”, Historia Constitucional, 22 (2021), pp. 360-394, https://doi.org/10.17811/hc.v0i22.685.

2. Antonio TRUEBA, “Notas autobiográficas”, La Ilustración española y americana, IV (1889), p. 59. 
por los personajes del relato, ${ }^{3}$ y también en muchas aprovecha para rememorar páginas de su vida, volviendo en distintos momentos sobre las que le habían causado una mayor impresión, eso sí, otorgándoles matices nuevos, cuando no visiones diferentes.

De estos momentos trascendentales, que dejan en Antonio Trueba un recuerdo indeleble, nos vamos a fijar principalmente en tres: el de la migración adolescente de su tierra natal, las Encartaciones vizcaínas; el de su reconocimiento como literato en el Madrid isabelino de la década de los cincuenta, y el de su afirmación como cronista y archivero de Vizcaya durante la década de los sesenta. Cada uno de estos tiempos lo adscribimos a un concepto nuclear que germina en ellos y después se potencia y desarrolla a lo largo de su obra. El primero lo vinculamos a la familia y a la aldea a la que pertenece; el segundo, a la Monarquía nacional católica isabelina, y el tercero a la comunidad foral vasca.

No son grandes ideas ni tampoco están presentadas con un lenguaje elevado porque el autor vizcaíno se caracteriza por una gran sensibilidad e ingenuidad, por un estilo de escritura llano y sencillo y por su cercanía y familiaridad ${ }^{4}$. Y es aquí en donde reside, a nuestro entender, el interés de la obra de Antonio Trueba: en su facilidad para llegar al público en general.

\section{El caserío de la amatxu}

La migración que se vio obligado a realizar cuando tenía 16 años a Madrid para evitar ser reclutado por los carlistas marcó la vida de Antonio Trueba de una manera crucial. La otra, que de nuevo le trajo a la capital entre 1873 y 1876, también impelido por la guerra carlista, debido a su anterior experiencia, edad madura y menor duración, fue mucho más llevadera ${ }^{5}$. La precedente fue la que le provocó una profunda nostalgia y melancolía, dejando una huella indeleble de ese tiempo y espacio abandonados. De ella derivaron, de una parte, esa citada ingenuidad y sencillez, a veces infantil, que perdura a lo largo de su vida y, de otra parte, debido a su carencia, un ensalzamiento de la familia, y particularmente de la madre, sobre todo a partir de las propias experiencias, y una idealización del mundo rural, que prioritariamente ilustra con el de su comarca natal de Las Encartaciones vizcaínas. Acabó profesando un verdadero culto al hogar nativo, fue familiarmente casero. Por el contrario, ese desplazamiento a edad tan temprana le produjo un acentuado rechazo a los espacios urbanos, a los viajes y a las migraciones, y

3. Para esta "presencia del yo", Montserrat Amores GARCíA, Antonio de Trueba y el cuento popular, Bilbao, Departamento de Cultura de la Diputación Foral de Bizkaia, 1999, pp. 50-51, y “Antonio Trueba y su obra literaria”, en Joseba AgIRREAZKUENAGA ZigorRAGA, y otros, Antonio de Trueba (1819-1889). Cronista de Bizkaia, Bizkaiko kronista, Museo de Las Encartaciones/ Juntas Generales de Bizkaia, Bilbao, 2020, pp. 125-129.

4. Lucien LOUIS-LANDE, “Un narrador español. Antonio Trueba”, traducción y anotación por Antonio Trueba de "Un Conteur espagnol contemporain - Antonio de Trueba", Revue des Deux Monde, $3^{\mathrm{r}}$ período, 13 (1876), pp. 410-432. Citado del texto recogido como apéndice en Cuentos del hogar, $2^{\mathrm{a}}$ edición corregida y aumentada, Imprenta y Librería de Miguel Guijarro, Madrid, 1876, p. 359.

5. Amores, Antonio de Trueba y el cuento popular, pp. 17-19, y Ricardo BeCERro BengoA, Trueba. Estudio biográfico, Madrid, La España Moderna, 1892, pp. 17-21. 
le hicieron muy receloso de lo foráneo y extranjero ${ }^{6}$. En definitiva, reacciones muy consecuentes con la época del romanticismo que vivió y cuyos ideales compartió.

Leyendo la narrativa de Antonio Trueba se descubre a un auténtico apologista de la familia, ante todo católica, cuya confesión profesa de manera ortodoxa. Por eso la considera una institución creada por Dios y la define como una especie de cuerpo fundado en el amor y el matrimonio santos para compartir las alegrías y tristezas, así como las cargas vitales. Además, es la expresión de la continuidad social, de la acumulación de esfuerzos y trabajos realizados a lo largo del tiempo, y también el depósito de la memoria y la tradición de los ascendientes. Con esta visión conservadora tan burkeana, sobre estas "hondas raíces" Antonio Trueba erige el hogar familiar, una especie de espacio protección, sentimientos, afectos y recuerdos que produce la felicidad doméstica que, según él, es la auténtica felicidad, que suple todas las carencias. De ahí que contemple a la familia como una segunda edición del paraíso terrenal ${ }^{7}$.

De esta manera, santificada, el modelo de familia, que preconiza el autor vizcaíno es el tradicional patriarcal, asentado en la "superioridad moral y física" del hombre, al que le incumbe el mantenimiento de sus miembros mediante el trabajo, la defensa del honor y del apellido familiar y la conservación del patrimonio de la casa solar, y en la supeditación de la mujer, a la que le corresponde el buen gobierno del hogar, el cuidado y educación de los hijos, y el amor, respeto y ayuda al marido. En ambos casos, como en la familia, el hombre y la mujer deben ser inexcusablemente buenos católicos ${ }^{8}$.

La catolicidad del primero la hace radicar, siguiendo las directrices de la Iglesia, en una vida morigerada y en el amor a la familia, en el cumplimiento de los deberes religiosos y en la preocupación por los demás, pero, fundamentalmente, en el trabajo. Considerado uno de los principios cardinales del pensamiento de Antonio Trueba, lo vincula, desde una perspectiva conservadora, a la respetabilidad y dignidad personal: "sin trabajo no hay honra". Por eso en el trabajo hace descansar el progreso personal y familiar, así como la organización y el progreso social. Pero también el orden y la estructura social existente. Para ello, lo integra en una especie de orden providencial:

6. Andrés GonZÁlez BlAnCo, Antonio Trueba: su vida y sus obras (páginas escogidas), Bilbao, Librería Villar, 1914, pp. 11-13; Gregorio MúGICA, Trueba: su significación en la moderna literatura vasca, San Sebastián, Imprenta Martín Mena y C a 1914, pp. 38-40, y Javier BARRIO MurO y Goio BAÑALES GARCíA, “Antonio Trueba y su visión de las Encartaciones” en AgIRREAZKUENAGA y otros, Antonio Trueba, pp. 32-33.

7. TruebA, Cuentos de color de rosa, $2^{a}$ ed. Hecha de orden y a expensas de S.M. la Reina, Madrid, Imp. de D. Luis Palacios, 1862, p. 297; Cuentos campesinos, $2^{a}$ ed. Hecha de orden y a expensas de S.M. la Reina, Madrid, Imp. de D. Luis Palacios, 1862, p. 132; El libro de las montañas, Bilbao, Librería de D. Agustín Emperaile, 1867, p. 184-188, y Mari-Santa, cuadros de un hogar y sus contornos, Madrid, A. de Carlos e Hijo, editores, 1874, p. 253.

8. Trueba, Cuentos de color de rosa, pp. 101 y 153; Cuentos campesinos, pp. 249 y 284; Cuentos populares, $2^{a}$ ed. Hecha de orden y a expensas de S.M. la Reina, Madrid, Imp. de D. Luis Palacios, 1862, p. 184, y Bosquejo de la organización social de Vizcaya. Publicase en virtud de acuerdo de este M.N. y M. I. Señorío, congregado en Junta General so el árbol de Guernica, Bilbao, Juan E. Delmas, impresor del Señorío, 1870, pp. 62-67. También Manuel GonzÁlez PorTILlA, Josetxo URRUTIKOETXEA LIZARRAGA y Karmele ZÁRRAGA SANGRÓNIZ, Vivir en familia, organizar la sociedad. Familia y modelos familiares las provincias vascas a las puertas de la modernización (1860), Bilbao, Universidad del País Vasco, Servicio Editorial, 2003, pp. 70-71, y PÉREZ NúÑEZ, "Didáctica para una nación católicoconservadora...”, pp. 561-562. 
"cada uno debe de estar contento con la ropa que Dios le ha dado" o, en otras palabras, debe aceptar la situación social que le ha correspondido. De esta manera, mediante esta estrecha ligazón con la resignación cristiana, el trabajo para el escritor vizcaíno se convierte en complemento $\mathrm{y}$, en situaciones de grave quebranto social (como la revolución gloriosa de 1868), sustituto de la fe religiosa ${ }^{9}$.

Antonio Trueba incide en la mujer, siempre católica, en muchos de sus cuentos y poemas, y al hacerlo, y así lo dice, sigue el modelo "pintado por Fernán Caballero [su gran referente literario y moral] con toda la magia de su admirable pincel, la mujer buena, honrada, santa, en sus fases de virgen y madre, de hija y esposa”. La primera fase es inexcusable para la segunda hasta el punto de convertirse en signo de honradez y respetabilidad no solo personal, sino familiar: la pérdida de la virginidad de una soltera constituye un auténtico oprobio para el apellido familiar. Así, "la mujer como Dios manda”, para el autor vizcaíno, manteniéndose "virgen sin mancilla”, debe educarse para cumplir el rol ya señalado dentro de la institución familiar ${ }^{10}$.

Una vez "trocada la condición de virgen por la no menos santa y noble de esposa y madre”, Antonio Trueba profundiza particularmente en ésta en su novela Mari-Santa. La mujer así llamada representa a una esposa y madre ejemplar, ferviente católica, cariñosa, bondadosa, abnegada, generosa, e incluso monárquica isabelina. Viene a ser el espejo de su madre, si bien en una escala social superior, ya que Mari Santa ejerce aquellas virtudes con los pobres, las criadas, los inquilinos y colonos viviendo en una suntuosa casa del entonces exclusivo Arenal bilbaíno, mientras su progenitora, Marta de la Quintana, las pone en práctica realizando las labores del hogar y en el campo colindante a su modesto caserío de Montellano (Sopuerta). Los retratos de mujeres sencillas, como su madre, son los que predominan en la obra literaria del autor vizcaíno y representan un modelo de mujer, que se encuentra a medio camino entre el ángel del hogar, arquetipo de la feminidad hegemónico en la cultura liberal, y la mujer católica del neocatolicismo conservador español.

El amor que Antonio Trueba desprende en Mari-Santa y otros relatos hacia su amatxu -la denominación "tan dulce y grata para los vascongados"11_ es particularmente profundo, porque después de abandonar de adolescente el hogar familiar nunca más la volvería a ver, al fallecer en 1851. Pues bien, ese amor lo hace extensivo y le confiere casi la misma intensidad que al anterior a la tierra en la que uno ha nacido, a la que contempla "como una segunda madre y se la debe querer como a la primera”. De ahí que la patria la suela identificar con la "aldea nativa”: "la patria del

9. TRueBA, El libro de las montañas, p. 152; El gabán y la chaqueta, Madrid, Imp. de T. Fortanet, 1872, pp. 378 y 454, y El redentor moderno, Madrid, Imp. y Librería de Miguel Guijarro, 1876, p. 393. Además, María Cruz RoMeO MATEO, "El otro género de la religión: la masculinidad católica en la España isabelina”, en Inmaculada BlASCO HERRANZ (ed.), Mujeres, hombres y catolicismo en la España contemporánea. Nuevas visiones desde la historia, Valencia, Tirant Humanidades, 2018, pp. 84-88.

10. Trueba, Cuentos populares, p. 180, y El libro de las montañas, p. 128. También PÉREZ NúÑEZ, “Didáctica para una nación católico-conservadora...”, p. 560.

11. TruebA, Cielo con nubecillas. Recuerdos de la vida rural y familiar de Vizcaya, Madrid, Imp. de A. Pérez Dubrull, 1871, pp. 50 y 69, y Mari-Santa, pp. 27, 32, 145 y 197. Además, Raúl MínguEz BLASCO, “Liberalismo y catolicismo ante el espejo. La construcción de las feminidades decimonónicas”, en BLAsco (ed.), Mujeres, hombres y catolicismo en la España contemporánea, pp. 25-45; y María Cruz RomeO MATEO, “¿Sujeto católico femenino? Política y religión en España”, Ayer, 106 (2017), pp. 95101. 
hombre es el mundo [...], pero mundo empieza donde uno ha nacido [...], allí donde principian mis deberes de amar, de agradecer y de proteger principia mi patria”.

Así, en este microcosmos es donde para el autor vizcaíno se alcanza la verdadera felicidad doméstica, al lograrse la perfecta armonía entre el medio físico y las familias que lo forman. Es un espacio seguro y definido, en el que uno se "siente como en casa". Por eso en sus narraciones no se cansa de presentar un paisaje rural paradisíaco, casi siempre representado por el de Las Encartaciones, y una bucólica vida campestre, fundada en el trabajo honrado y resignado del campo y en la sencillez y tranquilidad diaria del hogar en el caserío familiar. Parece claro que esta idealización es producto de una deformación de la realidad, ocasionada por la larga ausencia de su comarca natal y también por la afición de Antonio Trueba a la evasión romantizada ${ }^{12}$.

Pero el universo aldeano de nuestro escritor no está completo si no se cuenta con la parroquia y el cura que la preside. Ocupa la posición central de la vida comunitaria, tanto espiritual como social y cultural, ya que no es solo el lugar donde acuden los vecinos a la celebración de los oficios religiosos, sino también, bajo su pórtico, el sitio de esparcimiento y charla de los hombres de la aldea. Además, es el ámbito donde las familias logran amparo y cobijo en las situaciones de adversidad e infortunio, y también el punto de arranque de las festividades del pueblo. De esta manera, Antonio Trueba, como Fernán Caballero, encuentra en la aldea la verdadera religiosidad, las buenas y sanas costumbres y tradiciones, el amor a la familia, el respeto a la propiedad y a las jerarquías reconocidas, etc., es decir, una sociedad ejemplar de acuerdo con los parámetros morales católico-conservadores que profesaba ${ }^{13}$.

Por el contrario, las ciudades, como Madrid o las principales capitales europeas -que imagina de una manera bastante distorsionada y esperpéntica en alguno de sus cuentos, ya que nunca salió de España-, son la expresión de la modernización y del cambio, de la corrupción de costumbres y del desorden moral, de la quiebra de la comunidad y valores tradicionales. Pues bien, cuando parece que poco a poco iba superando su "aversión invencible a lo que no sé si llamar vida urbana”, es cuando se produce lo que para él supone una verdadera hecatombe, la Revolución Gloriosa. Entonces, el atractivo que había acabado teniendo el Madrid de la década de los cincuenta, como veremos en el siguiente apartado, se convierte en lo opuesto: es una ciudad lúgubre de los barrios bajos, del mundo de la noche, la miseria y la delincuencia, y al mismo tiempo, en la capital de las apariencias, que para él representa la buena sociedad madrileña, vacía de todo principio moral y puramente materialista. En

12. TRuebA, Cuentos de color de rosa, p. 39; Capítulos sentidos y pensados viajando por las provincias Vascongadas, Madrid, Centro General de la Administración, p. 42, y Cielo con nubecillas, pp. 45-46. También PÉREZ NúÑEZ, “La comunidad imaginada por Antonio Trueba...”, pp. 57-58

13. TruebA, Cuentos de color de rosa, p. 159; Cuentos populares, pp. 195 y 211-212; Cuentos del hogar, p. 309. También Belén AltunA, "La invención del baserritarra como verdadero cristiano vasco", Bitarte 22 (2000), pp. 6-8; Xavier ANDREu MiRAlles, El descubrimiento de España. Mito romántico e identidad nacional, Barcelona, Taurus, 2016, pp. 210 y 320-327; BARRIO y BAÑALES, “Antonio Trueba y su visión de las Encartaciones...”, pp. 47-56; LOUIS-LANDE, “Un narrador español...”, pp. 340-341, y PÉREZ NúÑEZ, “La comunidad imaginada por Antonio Trueba...”, pp. 64-65. 
definitiva, "Madrid -afirma Antonio Trueba- es un libro de inmoralidad abierto a todo el que tiene ojos en la cara" 14 .

El caso de la villa Bilbao resulta un tanto diferente. Antes de retornar a Vizcaya en 1862 y después residir en esa villa, la asimila, en gran medida, al resto de las ciudades, es decir, se encuentra en la antítesis a la idealizada aldea rural. Sin embargo, su visión varía con el cambio de 1868, porque "apenas se han alterado aún los buenos usos y las costumbres de la familia”. Por eso considera que la capital vizcaína cuenta con muchos de los rasgos que hacen felices y dichosos a los pueblos de la provincia. Afirma esto, no obstante, frente a la presión de la opinión liberal, dominante desde el otoño de 1870 tanto en el gobierno provincial como en el local, y que al final le obligará de nuevo a migrar a Madrid en el verano de $1873^{15}$.

\section{La monarquía nacional católica de Isabel II}

Antes de la revolución de 1868, durante los años centrales del reinado isabelino, todo nos hace pensar que el escritor vizcaíno se encontraba bastante a gusto en la capital de la Monarquía. Esta época constituyó para él otro de los momentos grabados a fuego en su memoria, en primer lugar, porque fue entonces cuando formó su propia familia, al contraer matrimonio en 1859 con la madrileña Teresa Prado García y tener al siguiente año a su hija Ascensión. Esto suponía la culminación de uno de sus principales ideales.

En segundo lugar, porque también durante este tiempo articuló una red de relaciones que, vinculadas fundamentalmente al ámbito periodístico y literario, le permitieron crear un grupo de amigos que perduraría a lo largo de su vida. Estas amistades, además, le facilitaron la entrada a la república de las letras, pudiendo dedicarse a la actividad periodística, destacando el puesto con el que desde 1853 contó en la redacción de La Correspondencia de España. Teniendo así medios para subsistir, igualmente esas relaciones le ayudaron a abrirse un hueco en el mundo literario, publicando sus primeras recopilaciones de poemas y cuentos, con las que alcanzó cierta popularidad y renombre.

Con este éxito, en tercer lugar, se le abrieron las puertas del círculo político cortesano de Isabel II, a la que siempre tendría en la más alta consideración. Tanto más cuanto para la monarca fue uno de sus autores preferidos - "el bardo querido de Isabel II”- y le patrocinó la reedición de alguna de sus obras. Esta es la razón por la que a ella, como a muchos de los que formaban parte de aquella esfera de afecto (José Castro, Luis Eguilaz, Pedro Antonio de Alarcón, Antonio Arnao, Carlos Pravía, Fernán Caballero o

14. TRueBA, Cuentos de color de rosa, pp.170-199; Capítulos sentidos y pensados viajando por las provincias Vascongadas, pp. 41-52; Cuentos de varios colores, Madrid, Imp. del Centro General de la Administración, 1866, pp. 101-172; El gabán y la chaqueta, pp. 72-78 y 99-101, y Cuentos de madres e hijos, Barcelona, Lib. de Juan y Antonio Bastinos, eds., 1878, pp. 78-103.

15. TruebA, Mari-Santa, p. 153; El redentor moderno, p. 154, y Madrid por fuera [reed. Alrededor de Madrid, 1874], Madrid, Agustín Jubera, 1878, p. 29. Para la visión dulce de Bilbao, Montserrat AMORES, “Antonio Trueba y Bilbao”, en Adolfo AREJTTA et al., Bilbao. El espacio lingüístico. Simposio 700 Aniversario. Bilboren 700. Urteurrena. Hizkuntza gunea Sinposioa, Universidad de Deusto, 2002, pp. 246-250, y para el contexto de su segunda emigración, Joseba AGIRREAZKUENAGA ZIGORRAGA, Joseba, "Patriotismo foral y gobierno de Bizkaia en tiempos de Antonio Trueba. Cronista, archivero y periodista", en Agirreazkuenaga y otros, Antonio Trueba (1819-1889). Cronista de Bizkaia..., pp. 319-323. 
Juan Eugenio Hartzenbusch), Antonio Trueba les tuvo presentes en las dedicatorias de los prólogos o en las propias narraciones y poemas de sus libros ${ }^{16}$.

En definitiva, Antonio Trueba se encuentra en la década de los cincuenta en un momento vital y profesional francamente grato. Si a esto unimos la tranquilidad de espíritu, derivada de la coincidencia, aceptación y reconocimiento de muchas de sus ideas, es fácil de comprender la participación con su narrativa en tarea de construcción y difusión del imaginario nacional católico conservador. De ahí que, rememorando este tiempo veinte años después, señalara "que puedo blasonar de que acaso soy entre todos sus hijos [de Vizcaya] el que más servicios ha prestado con la pluma a la causa de Dios, de la patria y de la familia, y acaso el primero que ha cantado su gloria, su honra y su hermosura" ${ }^{17}$.

El universo ideológico en el que transcurren las relaciones señaladas, incluidas las de la Corte isabelina, es el del liberalismo moderado, basculando al ala reaccionaria neocatólica. Lo comparte Antonio Trueba y con él orienta toda su obra literaria, que siempre está marcada por una particular finalidad instructiva y moralizadora, subordinándose cualquiera otra razón estética o narrativa. Así, con Fernán Caballero, entre otros, se suma a la tarea de contrarrestar los folletines y las llamadas novelas populares porque -advierte en El gabán y la chaqueta- con su "hipocresía populachera" dan pábulo a una moral en la que "de Dios, de la sociedad, de la familia y de la propiedad no quedaba ni rastro". De esta manera, casi toda su narrativa es exactamente lo contrario, la defensa y difusión de los principios y valores del catolicismo ortodoxo conservador.

Así, en las páginas de sus obras no solo se defiende la intolerancia religiosa y exclusividad católica imperante en la España isabelina porque la considere la "única verdadera”, sino que se denigra a las otras confesiones y, sobre todo, la incredulidad y el "racionalismo ateo". También, desde un catolicismo muy militante y apegado a la doctrina de la Iglesia (particularmente la difundida por el arzobispo de Santiago de Cuba y confesor de Isabel II, Antonio María Claret), catequiza a sus lectores en las virtudes teologales (la fe, la esperanza y la caridad), en el valor y la práctica de los sacramentos y en la figura tutelar de cura párroco, que siempre presenta como un ejemplo de vida y con un cierto halo de santidad. Más aún, muchos de los personajes de las narraciones del autor vizcaíno parece que están permanentemente guiados por el Catecismo del Padre Astete, que no solo les hace cumplir fervorosamente los sacramentos, los ritos y las celebraciones religiosas, sino que sujeta su conducta y principales pensamientos a la fe católica y a las directrices de la Iglesia. Además, otorga el refrendo confesional a los referentes fundamentales del ideario conservador, como la familia tradicional patriarcal, la dignidad del trabajo y el esfuerzo, la aceptación de la

16. Amores, “Antonio Trueba y su obra literaria...”, pp. 105-107 y 145-148; BeCERro, Trueba. Estudio biográfico, pp. 20-21; José Antonio EREÑo AltunA, Antonio de Trueba: literatura-historia-política (con la disculpa de unos artículos de Trueba), Bilbao, J. A. Ereño, 1998, pp. 29 y 82, y LOUIS-LANDE, “Un narrador español...” pp. 323-328.

17. TRuebA, Cuentos del hogar, p. 4. 
jerarquía y del orden social, el respeto a la propiedad y los derechos adquiridos y la fidelidad a las costumbres y tradiciones ${ }^{18}$.

Antonio Trueba asume el modelo social amparado por los moderados y también su régimen político doctrinario, si bien, como se puede constatar en alguna de sus narraciones cortas, se inclina por las propuestas reaccionarias de la tendencia monárquica o conservadora autoritaria, que defiende la necesidad de afirmar la autoridad monárquica y restringir el ámbito de las libertades ${ }^{19}$. Igualmente, de la misma manera que la familia moderada, tiene una visión de la nación y de la historia de España claramente retrospectiva y tradicional, identificando la Monarquía con el Estado y la consecución de la unidad política y religiosa, con el único fin de afirmar a la Monarquía isabelina como católica y nacional ${ }^{20}$. Sin embargo, en su caso no solo se identifica lo católico con lo nacional, sino que subordina esto a aquello: la nación al servicio de la religión. Así se desprende de la aportación que con sus cuentos y poemas realiza en la elaboración del relato nacional católico, en la que los grandes mitos fundacionales que difunde, como la reconquista, los reyes católicos y la guerra de la independencia, los aprehende desde esa particular visión historiográfica, es decir, siempre están definidos por el catolicismo.

En este discurso también se integra la Monarquía isabelina que, como para el grueso de los conservadores, se presenta como el fin de la historia, la síntesis de los tiempos $^{21}$. Pero además, para Antonio Trueba la reina es algo más: es "la madre de las madres”. Así la distingue en su novela Mari-Santa, en la que, aprovechando que la trama se desarrolla durante el reinado isabelino, narra el viaje que Isabel II realiza en 1865 a las provincias Vascongadas en el que él la acompaña y traza quizás su retrato más completo. La presenta como una "magnánima reina y tierna madre”, en la que los papeles se confunden porque trata a los españoles con la bondad, indulgencia, caridad, hospitalidad y piedad de una madre. De ahí que Mari Santa, la protagonista de esa narración y paradigma de madre para Antonio Trueba, "profese una entrañable adhesión a la reina [...] por afinidad de corazón de mujer y de madre”. Por eso, por recordarle y suplir en cierto modo a su progenitora, pero también por "el entusiasmo que raya el

18. TruebA, El gabán y la chaqueta, pp. 443 y 470-473; Cuentos de varios colores, pp. 15-17, y Cielo con nubecillas, pp. 157-158. También AMORES, Antonio de Trueba y el cuento popular, pp. 53-54 y 172174; ANDREU, El descubrimiento de España, pp. 210 y 320-327; Raúl MínGUEZ BlAsCO, Evas, Marías y Magdalenas. Género y modernidad católica en la España liberal (1833-1874), Madrid, Asociación de Historia Contemporánea/Centro de Estudios Políticos y Constitucionales, 2016, pp. 95-100; PÉREZ NúÑEZ, “Didáctica para una nación católico-conservadora...”, pp. 554-556 y 558-559, e Iris M. ZAVALA, "La literatura: romanticismo y costumbrismo”, en Hans JURETSCHKE (coord.), “La época del romanticismo (1808-1874)”, en José María Jover ZAMORA (dir.), Historia de España Menéndez Pidal t. 35, v. 2. Las letras, las artes, la vida cotidiana, Madrid, Espasa Calpe, 1989, pp. 123-125.

19. Trueba, Cuentos de varios colores..., pp. 5-10 y 204; Cuentos de vivos y muertos contados por el pueblo, Madrid, Lib. de Don Leocadio López editor, 1866, p. 134, y Cuentos populares...pp. 299-301.

20. Paloma Cirujano Marín, Teresa Elorriaga Planes, y Juan Sisinio PÉREz Garzón, Historiografía y nacionalismo español, Madrid, CSIC, 1985, pp. 91-98, y José María JOVER ZAMORA, La civilización española a mediados del s. XIX, Madrid, Espasa Calpe, 1991, pp. 165-169.

21. TruebA, El libro de los cantares, 5a ed., Madrid, Imp. de D. Luis Palacios, 1862, pp. 179-202, 373376 y 410; Cuentos campesinos..., pp. 210-211, y Cuentos de vivos y muertos contados por el pueblo, p. 90. También Francisco CÁnOVAS SÁnCHEZ, El partido moderado. Madrid, Centro de Estudios Constitucionales, 1982, pp. 303-308, y PÉREZ NúÑEZ, "Didáctica para una nación católicoconservadora...”, pp. 563-564. 
delirio" con el que los vascongados la reciben, el autor considera que "la ilustre mujer ocupará una de las páginas más gloriosas de la historia patria”22.

Esta ferviente fidelidad que profesa a Isabel II y que hace extensiva a los vascongados es acorde con la estrecha vinculación de las provincias de ambos con la Monarquía constitucional regentada por aquella y ordenada bajo los parámetros conservadores señalados. Lo es porque desde mediados del XIX, mediante la concertación entre los moderados y los fueristas -los moderados vascongados- con el beneplácito de la reina, se logra un acomodo de los regímenes forales vascos dentro de la Monarquía constitucional isabelina. A partir de aquí se desarrolla la doctrina del doble patriotismo español y vasco, a la que se suma Antonio Trueba, que supone compartir las dos identidades ${ }^{23}$.

\section{La arcádica comunidad foral-católica.}

El escritor vizcaíno estaba adscrito al fuerismo y, una vez afirmada como hemos visto la primera de las identidades, haría lo propio con la segunda. Lo haría, sobre todo, a partir de 1862, cuando regresó a vivir de forma estable a su provincia natal. Antonio Trueba, que desde su salida en 1836 no había vuelto hasta el viaje de novios a Las Encartaciones, retornó entonces para ocupar el puesto de archivero y cronista del Señorío de Vizcaya para el que había sido nombrado por las Juntas Generales de la provincia. La aceptación del cargo no fue una decisión fácil, porque en la capital estaba a gusto y bien considerado, contaba con cierto renombre en el mundo de las letras y sus amigos literatos abogaban para que se quedara. Al final, atraído por su pasado y su tierra, y por el prestigio del nuevo empleo, desoyó esos consejos, y todo indica que acertó, porque entonces se abrió, según su propia confesión, la etapa que, perdurando hasta su nuevo exilio a Madrid en 1873, sería la más feliz de su vida ${ }^{24}$.

En este tercer momento nuclear en su trayectoria vital, parece que se produce una coincidencia entre la realidad imaginada y la real, o, cuando menos, ésta colma sus expectativas. Así puede deducirse de las impresiones que le producen los paseos y excursiones que realiza al caserío paterno de Las Encartaciones desde su residencia, primero en Durango y después en Bilbao. Sensaciones que traslada a sus recopilaciones de cuentos, que sigue publicando y son una clara prolongación de las anteriores. Pero, además, en este tiempo desarrolla una labor ensayística que, viniendo a ser una síntesis teórica de su obra de ficción, está orientada a la legitimación de los regímenes forales. De esta manera, intentando satisfacer las expectativas puestas en él por las autoridades forales, se suma a otros literatos en la tarea de la invención de la tradición vasca,

22. TRUEBA, Mari-Santa, pp. 192-202.

23. Agirreazkuenaga, "Patriotismo foral y gobierno de Bizkaia...” pp. 270-284; Fernando MolinA APARICIO, La tierra del martirio español. El País Vasco y España en el siglo del nacionalismo, Madrid, Centro de Estudios Políticos y Constitucionales, 2005, pp. 102-105; PÉREZ NúÑEZ, "La comunidad imaginada por Antonio Trueba...”, pp. 52-55; José María PoRTiLlo VALDÉs, El sueño criollo. La formación del doble constitucionalismo en el País Vasco y Navarra, Donostia-San Sebastián, Nerea, 2006, pp. 170-176, y Coro RuBIO PoBES, La identidad vasca en el siglo XIX. Discurso y agentes sociales, Madrid, Biblioteca Nueva, 2003, pp. 153-168.

24. Trueba, Cuentos del hogar, p. 348; AgirreazkuenagA, "Patriotismo foral y gobierno de Bizkaia...” pp. 304-306; EREÑO, Antonio de Trueba, pp. 37-40, y GonZÁlez-Blanco, Antonio de Trueba, pp. 14-17. 
recurriendo a la difusión, de una parte, de los grandes mitos fueristas y, de otra, de la imagen idílica de universo rural vasco ${ }^{25}$.

A la primera tarea, a la difusión de los principales presupuestos en los que se querían sustentar los regímenes forales, como la independencia originaria, el monoteísmo primitivo, la incorporación pactada a la Corona de Castilla, el igualitarismo y el disfrute ancestral de las libertades, la limpieza de sangre y la hidalguía universal, contribuye, principalmente, mediante su réplica a las críticas vertidas en 1864 a las singularidades vascas en la prensa y la cámara alta por el senador andaluz Manuel Sánchez Silva y con El libro de las montañas, canto apasionado a un idílico y mítico País Vasco, con un largo apéndice que recoge una lectura eminentemente fuerista de la historia y de la ordenación de las provincias forales ${ }^{26}$. A la segunda, a la afirmación de la impronta ruralista, lo hace, fundamentalmente, con Bosquejo de la organización social de Vizcaya (1867), memoria indicada a afianzar la comunidad foral vizcaína ante la Corona, que fue presentada a la exposición universal de París de este año, recibiendo una mención honorífica, y con Cielo con nubecillas, recuerdos de la vida rural y familiar de Vizcaya (1871), una especie de adición fabulada al anterior ensayo con la que pretende solventar la anomalía de la migración que presenta el modelo social foral.

El reconocimiento en el informe final de esa mención de la comunidad foral vizcaína como “una Jauja o Eldorado español”, particularmente en lo que se refiere al ámbito rural, es lo que permite a Antonio Trueba presentarla como una estructura social modélica. Para él es el resultado lógico de una conjunción perfecta entre un pueblo virtuoso, como el vasco, y una constitución ancestral, idónea e intangible a la mudanza de los tiempos, como son los Fueros.

El primero, con unos orígenes remotos y asentado en un medio físico favorecido por la naturaleza, es ejemplar de acuerdo con los cánones conservadores. Así, al igual que Fernán Caballero procede con el pueblo andaluz, el escritor vizcaíno caracteriza al vasco por ser profundamente religioso, amante de la familia y de su tierra, fiel a las buenas costumbres y tradiciones, leal, emprendedor y morigerado, respetuoso con el orden, la autoridad, la propiedad y las jerarquías sociales, etc. Tiene todos los elementos para alcanzar la felicidad pensada por Antonio Trueba.

El segundo, el modelo foral, lo legitima conforme a la concepción históricotradicional de Constitución, es decir, es una estructura adaptada ancestralmente a las condiciones específicas de la sociedad vasca. Pero que, para Antonio Trueba, no es solo beneficiosa, a la manera burkeana, porque ha perdurado a lo largo del tiempo (siendo, por ello, la prescripción el más sólido de sus títulos), sino porque, además se acomoda a todas las circunstancias y momentos, sin tener que realizar adecuación alguna; siempre presenta la organización política más libre y avanzada. De esta manera, el código foral, cuyos orígenes se pierden en el tiempo, viene a ser una especie de carta otorgada por la divinidad.

De la intersección del pueblo vasco y sus Fueros Antonio Trueba hace surgir la organización agraria del caserío que, estrechamente ligada a la institución también

25. José Luis DE LA GRANJA, Justo BerAmendi y Pere ANGUERA, La España de los nacionalismos y las autonomías, Madrid, Síntesis, 2003, pp. 35-37, y Jon JuARISTI, El linaje de Aitor. La invención de la tradición vasca, Madrid, Taurus, 1987, pp. 107-167.

26. Antonio Trueba, Defensa de un muerto. Réplica a los cinco artículos publicados por Manuel Sánchez Silva sobre la unidad constitucional, Bilbao, Imp. y lit. de Juan E. Delmas, 1865, y El libro de las montañas, pp. 259-320. 
nuclear de la ya mencionada familia de carácter patriarcal, la perpetúa en el tiempo gracias al trabajo generalizado e ininterrumpido de todos sus miembros y a la sucesión troncal. Los distintos caseríos familiares, agrupados en aldeas en torno a parroquias, configuran para el narrador vizcaíno, como ya hemos visto, una especie de comunidad, que les complementa y les permite un desarrollo social armónico y un alto grado de bienestar. En definitiva, sentencia el escritor vizcaíno, "el espíritu democrático y de igualdad social reinan en las provincias vascongadas desde tiempo inmemorial"27.

Para llegar a esta conclusión distorsiona un tanto la realidad para que, a la manera de La democracia en América de Alexis de Tocqueville, impere la igualdad de condiciones. Así, Antonio Trueba solventa la discriminación que produce el sistema troncal, compensando a los hermanos excluidos en la herencia, y las posibles diferencias entre los mayoritarios inquilinos y minoritarios propietarios, articulando entre ellos unas relaciones armónicas y cuasi familiares. Pero la única manera que tiene para hacer que prospere la igualdad política masculina, en donde como en las demás provincias del Estado rige el restrictivo sistema censitario moderado para la elección de todas las instituciones, es mediante una afirmación falsa ("que casi siempre comparten la honra y el trabajo del gobierno del Señorío el rudo labrador que viste chaqueta y el culto hacendado que viste levita”), pero que, a él, como a otros fueristas, le vale y por eso la repite $^{28}$.

Resueltos de esta manera los posibles desajustes, el único problema que tiene para su autor la construcción foral es la migración. Considera que se puede remediar manteniendo la organización ejemplar del caserío, afirmando el valor del trabajo y del esfuerzo constantes e introduciendo nuevas formas de explotación de los recursos naturales. Pues bien, cumpliendo estas premisas, y teniendo una familia "como Dios manda” y una profunda fe religiosa, Ignacio Gallardo, baserritarra de la narración Cielo con nubecillas, consigue convertirse "en un rico indiano sin ir a las Indias" ${ }^{29}$.

\section{Epílogo: Agur al mundo “como Dios manda”}

Las carencias de la familia y de la aldea natal debidas a la migración adolescente produjeron en Antonio Trueba su ensalzamiento. Para él la primera, además de ser una institución fundada en el matrimonio católico, es la expresión de la continuidad social (propiedad, memoria y tradición). Tiene un carácter tradicional patriarcal y, para que tanto el hombre como la mujer puedan cumplir los roles correspondientes, los vincula, respectivamente, al trabajo y al amor maternal. La catolicidad siempre debe imperar en ambos y también en la aldea, en la que la parroquia ocupa una posición central en la vida comunitaria de las familias.

27. TRueBA, Bosquejo de la organización social de Vizcaya...pp. 22-34, 62-67 y 91-92, y El gabán y la chaqueta, p. 215. También AgIRreAzKuenAgA, "Patriotismo foral y gobierno de Bizkaia...”, pp. 313314; PÉREZ NúÑEZ, “La comunidad imaginada por Antonio Trueba...”, pp. 56-59 y 66-68, y PORTILLO, El sueño criollo, pp. 197-199.

28. TruebA, Bosquejo de la organización social de Vizcaya, p.46; Pérez Núñez, "La comunidad imaginada por Antonio Trueba...”, pp. 67-68; MolinA, La tierra del martirio español, pp. 94-95, y Mikel URQUiJO GoITIA, Dos aproximaciones a la sociedad vasca del ochocientos, Bilbao, Servicio Editorial de la Universidad del País Vasco, 2000, pp. 28-29.

29. TruebA, Cielo con nubecillas, pp. 77 y 119; AltunA, “La invención del baserritarra...”, pp. 5-8, y AmORES, “Antonio Trueba y su obra literaria...”, pp. 141-142. 
La patria chica de la aldea queda en un segundo plano cuando en la capital de la grande se siente reconocido y realizado como literato afamado. Entonces se pone al servicio de la Monarquía isabelina católica y conservadora, y colabora con su obra literaria en su consolidación, divulgando la doctrina y los preceptos religiosos, confiriendo el refrendo confesional a los principios y referentes fundamentales del modelo social y político moderado, afirmando a la Monarquía isabelina como nacional y católica a través de sus mitos fundacionales y difundiendo una imagen eminentemente maternal de Isabel II.

Siendo los moderados y los fueristas vascongados ideológicamente afines, Antonio Trueba no tiene problema alguno en ponerse a disposición de estos desde el puesto de archivero y cronista de Vizcaya. Desde aquí participa en la labor de la consolidación ideológica de los regímenes forales, dotándoles de un sustrato histórico, tradicional y mítico y de un imaginario arcádico ruralista. Éste lo resume en la conjunción de un pueblo virtuoso, como el vasco, y una Constitución ancestral, como los Fueros, que dan como resultado la organización agraria del caserío, el cual, integrado en una comunidad parroquial, permite un desarrollo social armónico y un alto grado de bienestar.

Para Antonio Trueba, tanto la familia, y la aldea a la que pertenece como la Monarquía isabelina y la comunidad foral vascongada están aunados por la religión católica: "son como Dios manda." Pues bien, todo este mundo se derrumba con la Gloriosa Revolución de 1868 que, para el autor vizcaíno, supone poner fin a treinta años de prosperidad y engrandecimiento. Más terrible es aún desde la visión apocalíptica donosiana y desde las doctrinas antimodernas y antiliberales contenidas en los preceptos de Pío IX, que comparte con los neocatólicos y tradicionalistas.

Así, situado en una posición de vehemente militancia católica ortodoxa, para Antonio Trueba la revolución supone la ruptura con todo lo existente $y$, fundamentalmente, es consecuencia del reconocimiento de la libertad de cultos y del subsiguiente proceso de laicización. Con ello, terminando con el exclusivismo católico, para el autor vizcaíno se clausuran siglos de historia que habían definido la identidad de España y de los españoles: "la unidad religiosa de nuestra patria, que ya no pueda dar el nombre de católica”. España deja de ser católica y la gloriosa corona de su trono secular rueda por los suelos, señala con tristeza Antonio Trueba. Pero además, al no existir contención alguna para "las ideas inmorales y disolventes", lo que finalmente ocurre es "que los mandamientos de Dios se vuelven al revés [...] que de Dios, de la sociedad, de la familia y de la propiedad no queda siquiera rastro" 30 .

Para el escritor vasco, el País Vasco, debido a la lealtad de sus habitantes a Isabel II, al disfrute ancestral de los regímenes forales y al profundo sentimiento religioso, se queda al margen de las transformaciones de la Gloriosa y representa -en palabras de El Correo Vascongado, del que es redactor- "un delicioso oasis en el desierto revolucionario de España”. Sí es un oasis, pero dominado por un fuerismo tradicionalista y carlista, contrarrevolucionario. Por eso de nuevo se levanta en armas e inicia una nueva guerra. Antonio Trueba, aunque comparta muchas de las ideas de los sublevados, disiente del recurso a la violencia y es fiel a Isabel II. De ahí que se sume a la empresa canovista de la Restauración, pero siempre la entiende como una

30. TruebA, El gabán y la chaqueta, pp. 12, 443 y 448, y Mari-Santa, p. 77. También EREÑO, Antonio de Trueba, p. 38. 
PÉREZ NÚÑEZ

recuperación en toda su amplitud de la Monarquía nacional y católica isabelina, su verdadero ideal $^{31}$.

31. TrueBA, El gabán y la chaqueta, pp. 464-466; Mari-Santa, pp. 192 y 217, y El redentor moderno, p. 38. También PÉREZ NúÑEZ, “Antonio Trueba ante la Revolución de 1868...”, p. 372. 